\title{
Low Cost Seismic Network Practical Applications for Producing Quick Shaking Maps in Taiwan
}

\author{
Chih-Yih Hsieh ${ }^{1}$, Yih-Min Wu ${ }^{1, *}$, Tai-Lin Chin ${ }^{2}$, Kuan-Hung Kuo ${ }^{1}$, Da-Yi Chen ${ }^{1,3}$, Kai-Shyr Wang ${ }^{4}$, \\ Ya-Ting Chan ${ }^{1}$, Wen-Yen Chang ${ }^{5}$, Wei-Sen $\mathrm{Li}^{6}$, and Shaw-Hsung Ker ${ }^{6}$ \\ ${ }^{1}$ Department of Geosciences, National Taiwan University, Taipei, Taiwan \\ ${ }^{2}$ Department of Computer Science and Information Engineering, National Taiwan University of \\ Science and Technology, Taipei, Taiwan \\ ${ }^{3}$ Central Weather Bureau, Taipei, Taiwan \\ ${ }^{4}$ Department of International Cooperation, National Science Council, Taipei, Taiwan \\ ${ }^{5}$ Department of Natural Resources and Environmental Studies, National Dong Hwa University, Hualien, Taiwan \\ ${ }^{6}$ National Science and Technology Center for Disaster Reduction (NCDR), New Taipei City, Taiwan
}

Received 30 September 2013, revised 13 March 2014, accepted 27 March 2014

\begin{abstract}
Two major earthquakes of $\mathrm{M}_{\mathrm{L}}$ greater than 6.0 occurred in Taiwan in the first half of 2013. The vibrant shaking brought landslides, falling rocks and casualties. This paper presents a seismic network developed by National Taiwan University (NTU) with 401 Micro-Electro Mechanical System (MEMS) accelerators. The network recorded high quality strong motion signals from the two events and produced delicate shaking maps within one minute after the earthquake occurrence. The high shaking regions of the intensity map produced by the NTU system suggest damage and casualty locations. Equipped with a dense array of MEMS accelerometers, the NTU system is able to accommodate 10\% signals loss from part of the seismic stations and maintain its normal functions for producing shaking maps. The system also has the potential to identify the rupture direction which is one of the key indices used to estimate possible damage. The low cost MEMS accelerator array shows its potential in real-time earthquake shaking map generation and damage avoidance.
\end{abstract}

Key words: Earthquake, Damage earthquake, Shaking map, MEMS accelerometer

Citation: Hsieh, C. Y., Y. M. Wu, T. L. Chin, K. H. Kuo, D. Y. Chen, K. S. Wang, Y. T. Chan, W. Y. Chang, W. S. Li, and S. H. Ker, 2014: Low cost seismic network practical applications for producing quick shaking maps in Taiwan. Terr. Atmos. Ocean. Sci., 25, 617-624, doi: 10.3319/TAO.2014.03.27.01(T)

\section{INTRODUCTION}

Taiwan is located on the convergent zone between the Philippine Sea Plate and the Eurasian Plate. The measured convergence rate of the two plates is about $80 \mathrm{~mm}$ per year (Yu et al. 1997). Therefore, there are high crustal deformations and frequent earthquake activities around Taiwan. Occasionally, a large earthquake can cause serious damage.

In the first half of 2013 two major earthquakes of $\mathrm{M}_{\mathrm{L}}$ greater than 6.0 occurred in Nantou County, Taiwan (Fig. 1). The vibrant shaking caused landslides and falling rocks, and resulted in many casualties. By quickly producing shaking maps near the epicenter shaking intensities are understood and damage estimated. Emergency responses can also start within a few minutes after a damaging earthquake occur-

\footnotetext{
* Corresponding author

E-mail:drymwu@ntu.edu.tw
}

rence (Wu et al. 2002, 2003, 2004).

A shaking map is a contour figure illustrating the Peak Ground Acceleration (PGA) distribution collected from different strong motion stations over a geographical area. A seismic network with high density strong motion stations can enhance the PGA map resolution. However, the high cost of traditional seismometers prevents broader installation. Because a high resolution PGA map is important for damage estimation and emergency responses, a low cost alternative is desperately needed to facilitate shaking map generation.

MEMS (Micro-Electro Mechanical System) accelerometers have been introduced in seismic applications since the 1990's (Holland 2003). The miniature devices provide an ideal, cost-saving solution for recording strong ground motion signals. Therefore, MEMS devices have been widely 
used in developing large-scale, dense seismic networks ( $\mathrm{Wu}$ et al. 2013a).

The Quake-Catcher Network (QCN), a crowd-sourcing seismic network, is designed to collect PGAs through Internet-connected personal computers equipped with internal or external MEMS accelerometers. The QCN is operated by global volunteers who record and share seismic records. The network is appropriate for detecting moderate and large quakes (Cochran et al. 2009).

In October 2007 Japan began a new service, Earthquake Early Warning (EEW), for its residents provided by the Hi-net seismic network (Hi-net). The average distance between two stations in Hi-net is about $25 \mathrm{~km}$. A challenge to Hi-net is it needs to deploy seismic sensors with higher density in the epicenter vicinity. An estimation shows that more than 10-times the present number of sensors are needed to meet the demand and the cost is not affordable for the Japanese government. An alternative solution, called home seismometer, combines low-cost MEMS accelerometers and $\mathrm{A} / \mathrm{D}$ converters for earthquake early warning at home and office (Horiuchi et al. 2009).

In 2010 the research team at NTU initiated a pilot experiment by installing a seismic network with 15 MEMS accelerometers, named "Palert", in Hualien County (Wu and Lin 2014). The experimental deployment shows the potential of using MEMS devices for detecting and recording earthquakes in Taiwan. The Hualien network outcome demonstrates good performance and high reliability of the Palert devices. Based on the pilot project, the network was extended to other areas of Taiwan. Currently, 401 stations were installed by first quarter of 2013 (Fig. 1; Wu et al. 2013a). Most of the stations are located in elementary schools where power and Internet connections are provided. Therefore, the cost of building the network was reduced. Whenever an earthquake occurs around Taiwan a shaking map can be produced within one to two minutes based on the data collected by the NTU network. The two major earthquakes mentioned above are used as examples in this

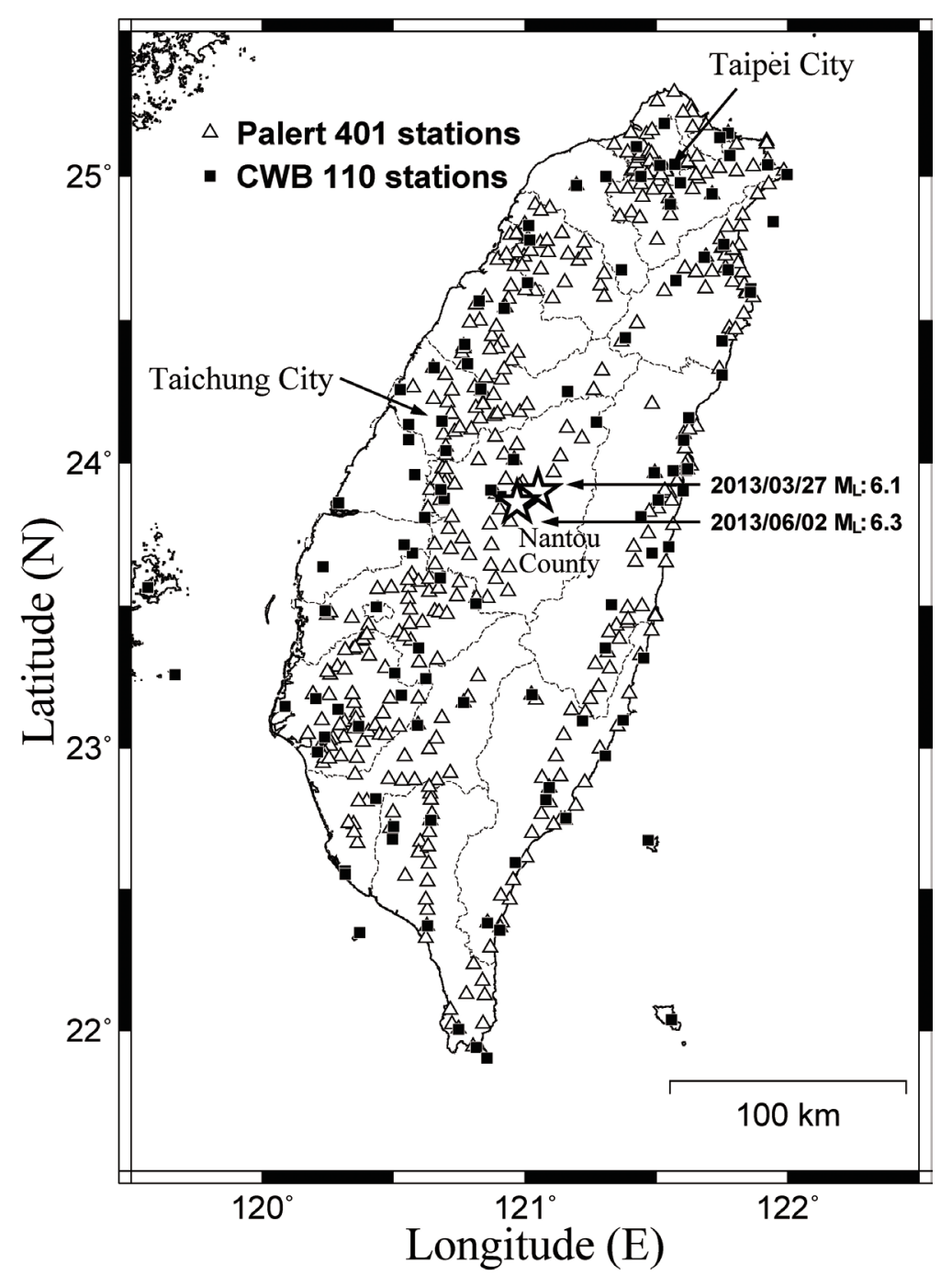

Fig. 1. The station distribution of the NTU Palert and CWB earthquake early warning system. 
paper to illustrate the latest NTU network developments.

\section{LOW COST SEISMIC NETWORK}

Since 1995 the Central Weather Bureau (CWB) has been operating a government-supported EEW system covering the $35900 \mathrm{~km}^{2}$ area of Taiwan. The EEW system run by the CWB includes 109 real-time stations composed of traditional force-balanced accelerometers. The distance between the stations is about $30 \mathrm{~km}$. According to the ElarmS outcomes adopted by Northern California, ideal seismic monitoring grid spacing for earthquake early warning is about $20 \mathrm{~km}$ or less (Allen et al. 2009). Due to the more complicated topography and geological properties in Taiwan, the station spacing should be finer. Similar to Japan, the financial considerations (Horiuchi et al. 2009) involved in traditional force-balanced accelerometers are not appropriate for Taiwan. Instead, a seismic network with MEMS accelerators is a better solution for EEW in Taiwan (Wu et al. 2013a; Wu and Lin 2014).

The Palert is a $\mathrm{P}$-wave detecting device, which is a joint product designed and manufactured by the NTU research team and a private corporation. Using MEMS technology, it is a light-weight, low-cost device. Its cost is less than onetenth that of the traditional strong motion instruments. The device is designed to record three-dimensional acceleration signals in real-time. The signal resolution is 16 bits with a measurement range from -2 to $+2 \mathrm{~g}$. The software algorithm enables the device to capture the initial P-waves and estimate parameters like peak amplitude of displacement (Pd) as it is triggered. When the up-coming seismic waves estimation exceeds the configured thresholds, Pd larger than $3.5 \mathrm{~cm}$ or PGA larger than 80 gal, the device starts sending alarms for onsite EEW purposes (Kanamori 2005; Wu and Kanamori 2005a, 2005b; Wu et al. 2011, 2013a).

The Palert is more than a stand-alone device. It can be connected as a regional or front-detection EEW system (Kanamori 2005; Wu and Kanamori 2005a) though the Internet and provide a real-time shaking map. Palert EEW system results have been reported by $\mathrm{Wu}$ et al. (2013a). We focus on the real-time shaking map system in this paper. Figure 2 shows the system configuration of the Palert network. For seismic data processing real-time signals are delivered from local sites to the central station in NTU via the Internet. At the central station signals are processed and stored within the Earthworm system developed by the United States Geological Survey (Johnson et al. 1995). The real-time signals are also shared with the shaking map program developed in this study through a shared memory to produce a real-time shaking map.

\section{REAL-TIME SHAKING MAPS OF THE 2013 NANTOU EARTHQUAKES}

Two consecutive shallow earthquakes occurred in Central Taiwan on 27 March $\left(M_{L} 6.1\right)$ and 2 June $\left(M_{L} 6.3\right)$ in 2013. The focal depth of the former quake is $19.4 \mathrm{~km}$ and the latter one is $14.5 \mathrm{~km}$ reported by the CWB rapid reporting system. This is a well-known earthquake location region by the CWB seismic network (Chang et al. 2012; Wu et al. 2013b). Both epicenters are located in Nantou County with a distance less than $8 \mathrm{~km}$ (Fig. 1). Chuang et al. (2013) studied the causative faults of these two events. The strong motion records analysis from the epicentral regions show that acceleration durations exceeding 250 gal were recorded in both events in less than two seconds. Acceleration duration

\section{Shaking Map Processing Configuratior}

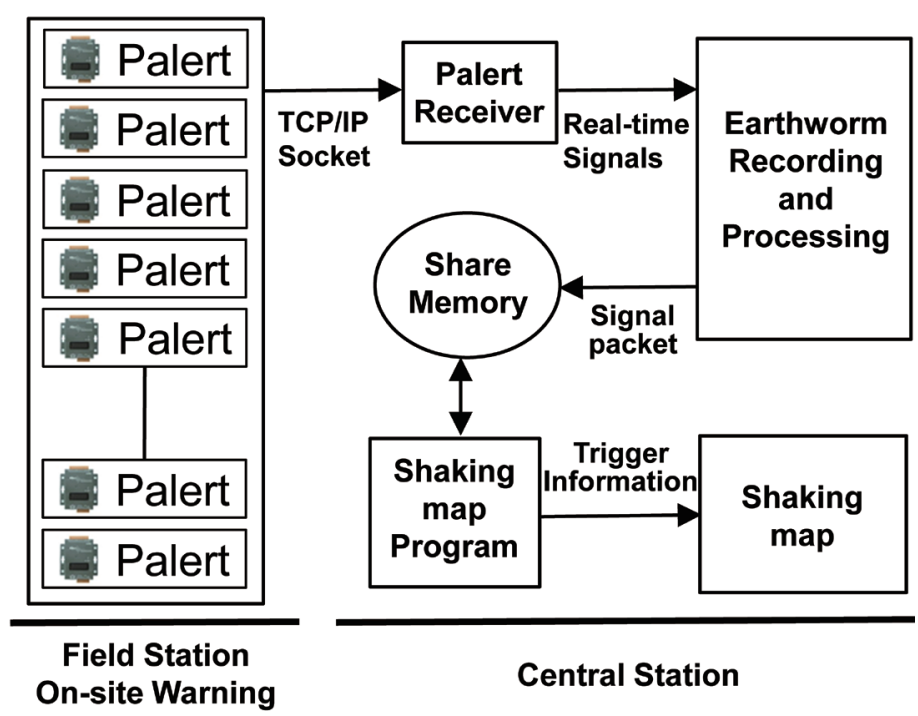

Fig. 2. Configuration shaking map processing of the Palert network. 
greater than $80 \mathrm{gal}$ was recorded in the latter event.

No ground ruptures were observed after the two events. However landslides and falling rocks were reported. In March, the first Nantou earthquake claimed one life, injured 97 and most casualties occurred in Taichung City and Nantou County. The Taiwan High Speed Rail suspended its service to check for possible damage. The second Nantou earthquake took four lives and wounded 77 . The casualties were distributed mainly in Nantou County. Power supply was temporarily interrupted in some districts. In Nantou County serious landslides were found at four sites. The largest landslide area was about 14 hectares and a 0.2-hectare barrier lake was also reported due to falling rocks blocking a river channel.

These two earthquakes provided a test platform to verify the performance and quality of the NTU seismic network. From the outcomes the central station received high quality strong motion signals (Fig. 3) and generated shaking maps within one minute after the earthquake occurrence. The NTU network has more than three times the number of stations compared to the CWB's system. Taking the advantage of the higher station density the NTU network produces a more accurate and refined shaking map (Fig. 4).

With a relatively sparse number of stations the CWB system generates a decent shaking map. There are 401 stations in the NTU system, with each station covering an average area of $90 \mathrm{~km}^{2}$. Figure 5 shows the damage and casualty drawn drawn with respect to the higher shaking regions in the intensity map produced by the NTU system.

A series of aftershocks occurred after the main shocks. The locations are close to the main shock epicenter. The stations recording the high intensity shock and aftershocks were distributed in the west-north-west direction from the first event observation. The main-shock epicenter is located at the east-south-east corner of the high-intensity zone. Therefore, a rupture could proceed from the hypocenter along the

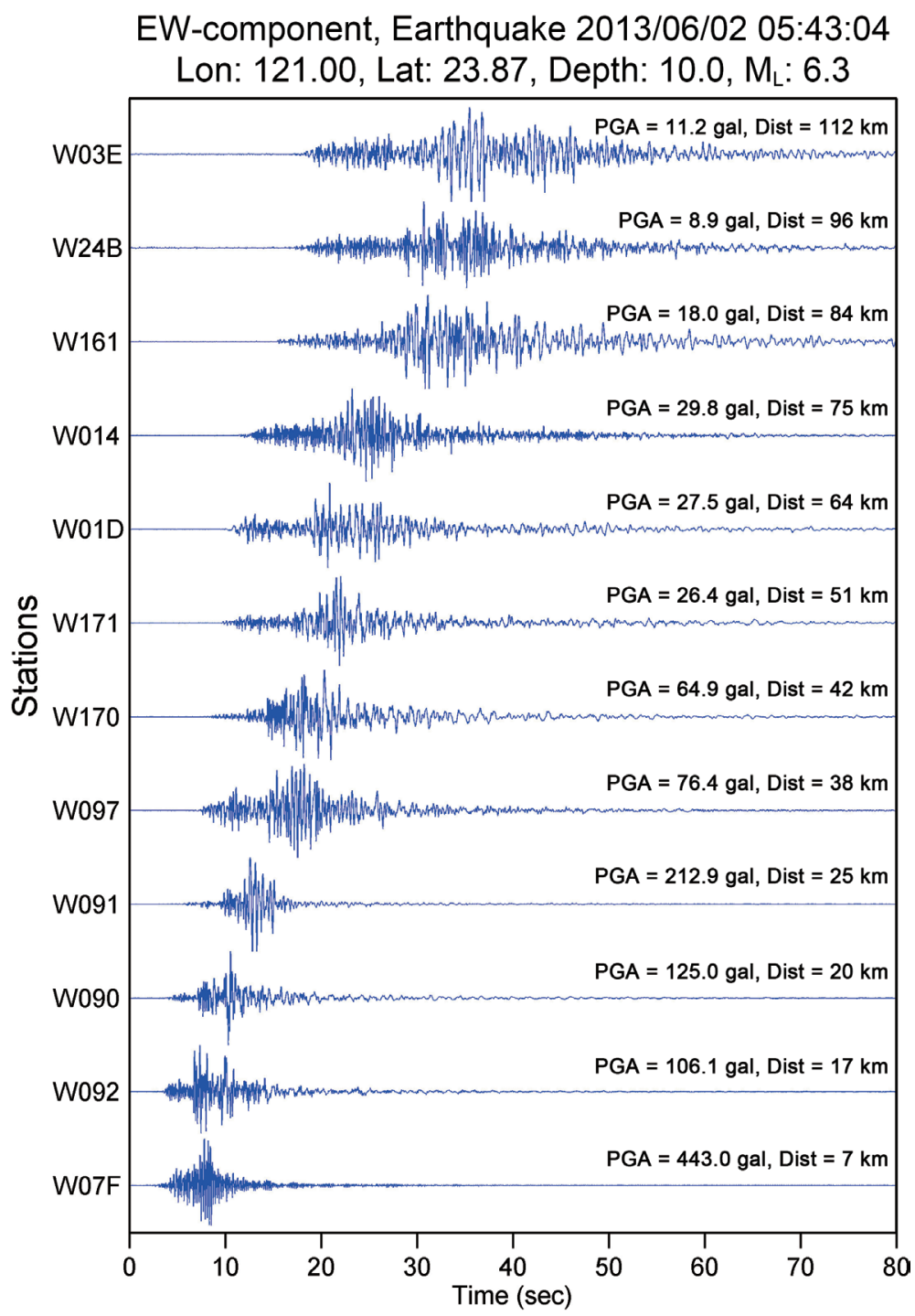

Fig. 3. Strong motion records from the 2 June $2013 \mathrm{M}_{\mathrm{L}}$ 6.3, Nantou Earthquake recorded by the Palert network. 

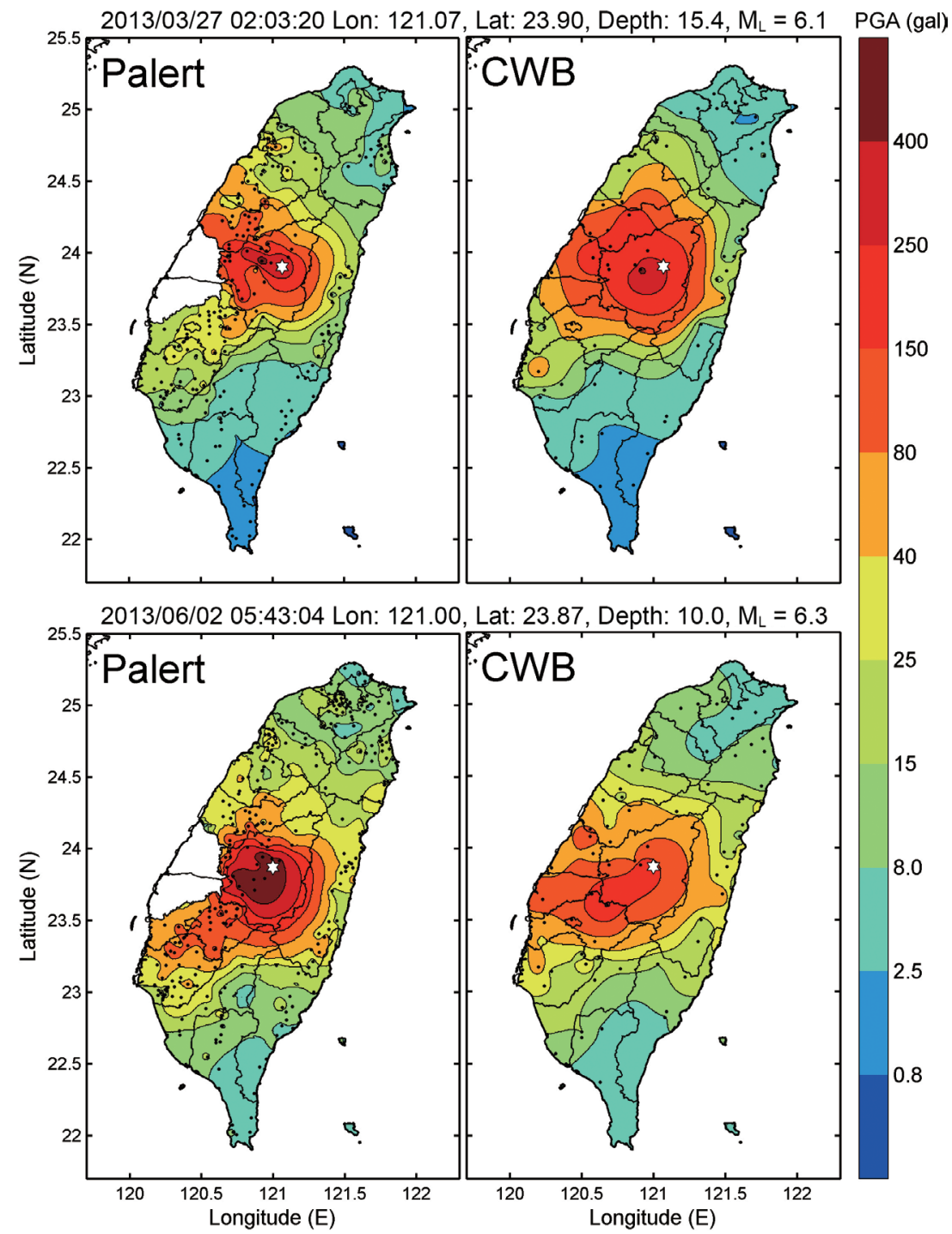

Fig. 4. Shaking maps for the 27 March and 2 June 2013 Nantou earthquakes produced by Palert and CWB. Dots indicate stations distribution of the CWB and Palert network for plotting shaking map.

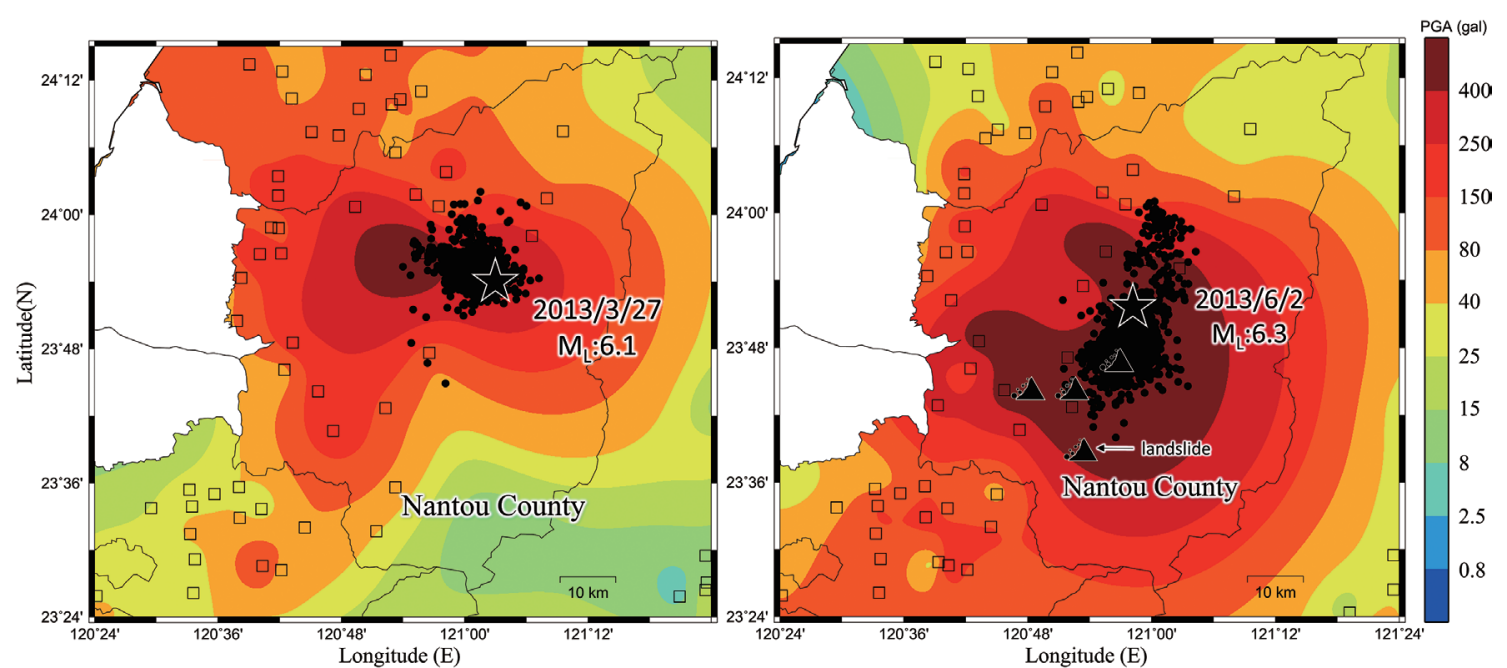

Fig. 5. Most aftershocks following the two Nantou earthquakes occurred in high seismic intensity regions. The open squares show the Palert Network station distribution. 
west-north-west direction, resulting in high seismic intensity distributed in the west-north-west direction.

The high intensity regions of the second Nantou earthquake and the aftershock distribution are located along the west-south-west direction from the epicenter. There were several aftershocks recorded in the east-north-east direction from the epicenter. This may imply that ruptures could be in two directions. The main rupture went west-south-west and the other was along the east-north-east.

Identifying the rupture direction is one of the key indices used to estimate possible damage after an earthquake occurs. This process depends on the aftershock focal mechanism and spatial distribution. A fault-plane solution can be performed in several minutes after an earthquake occurs, but a period of time is needed to understand the aftershock distribution. There are a number of current optional methodologies to estimate the rupture direction, but all of these methods require more time to analyze the data. Figure 5 shows that most of the aftershocks following the two Nantou earthquakes occurred in high seismic intensity regions. In the future, if the focal mechanism is acquired, we might estimate the rupture plane accurately as mentioned above. It will be helpful for damage assessment. However, more efforts are still in the future.

Another $\mathrm{M}_{\mathrm{L}} 6.4$ event occurred on 31 October 2013 in Hualien County. It also showed a high shaking region consistent with the aftershock distribution. Figure 6 shows the shaking map for the 2013 Hualien earthquake and the aftershock distribution. The aftershock locations are close to the main shock epicenter. The stations recording the high intensi-

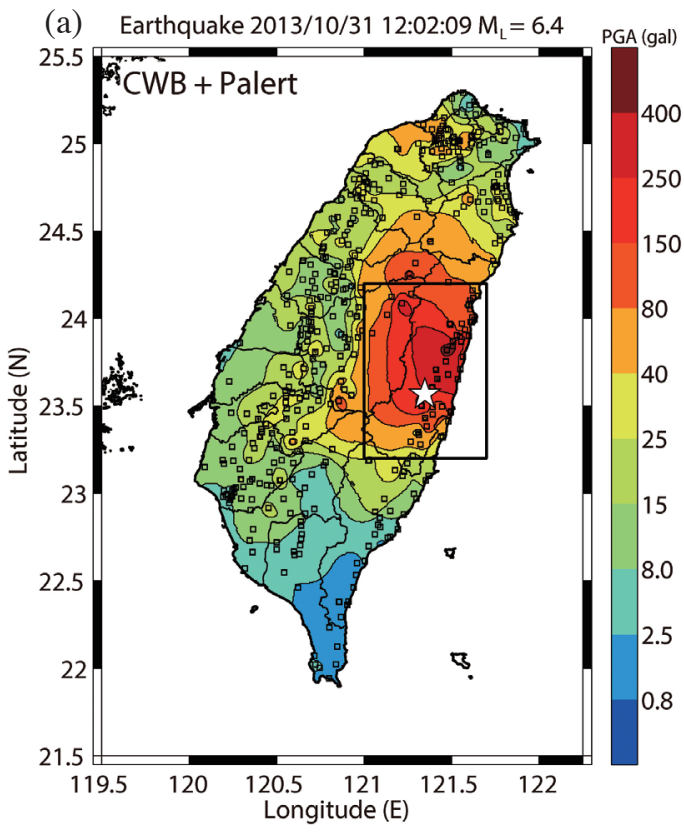

ty shock and aftershocks were distributed in a direction north of the main shock. Therefore, the rupture could proceed from the hypocenter along the north direction, resulting in high seismic intensity distributed in the northern direction.

\section{DISCUSSION AND CONCLUSIONS}

Considering electricity and telecommunications service disruptions after a major earthquake, seismic network operations could be partially or totally suspended. Especially in a sparse-grid network, one or a few stations down could severely affect network operations. In contrast, the dense grid of the NTU system is able to accommodate signal loss from a portion of the seismic stations and still maintain its normal functions, including producing shaking maps within one minute and assisting in loss estimation and emergency operations. The NTU system may be capable of calculating the characteristics and source rupture parameters, which are not possible for a sparse network. Figure 7 shows the near epicentral strong motion records from the 2 June $2013 \mathrm{M}_{\mathrm{L}} 6.3$, Nantou Earthquake recorded by the NTU Palert network. A few stations could not send data to the central stations, as generally occurs after $\mathrm{S}$ waves. This phenomenon may be caused by the short instability of both power and the Internet during and after large shakings. During this event about $10 \%$ of the stations could not transfer signals to the central station. However, the other $90 \%$ stations kept the system smoothly in operation (Wu et al. 2013a).

Now the number of Palert stations in the NTU system exceeds 400 and the installation process is still on going.

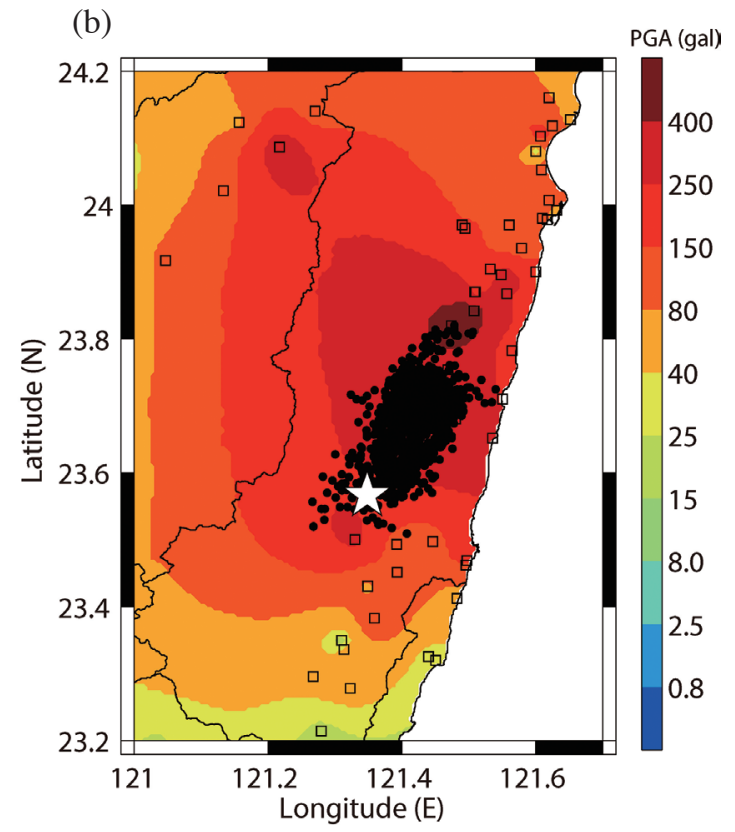

Fig. 6. (a) Shaking map for the 31 October 2013 Hualien earthquake produced by the strong motion records from both NTU Palert and CWB networks. Star shows epicenter and open squares indicate the CWB and Palert network station distribution for plotting the shaking map. (b) Shaking map for epicentral regions. Dots show the aftershock distribution. 


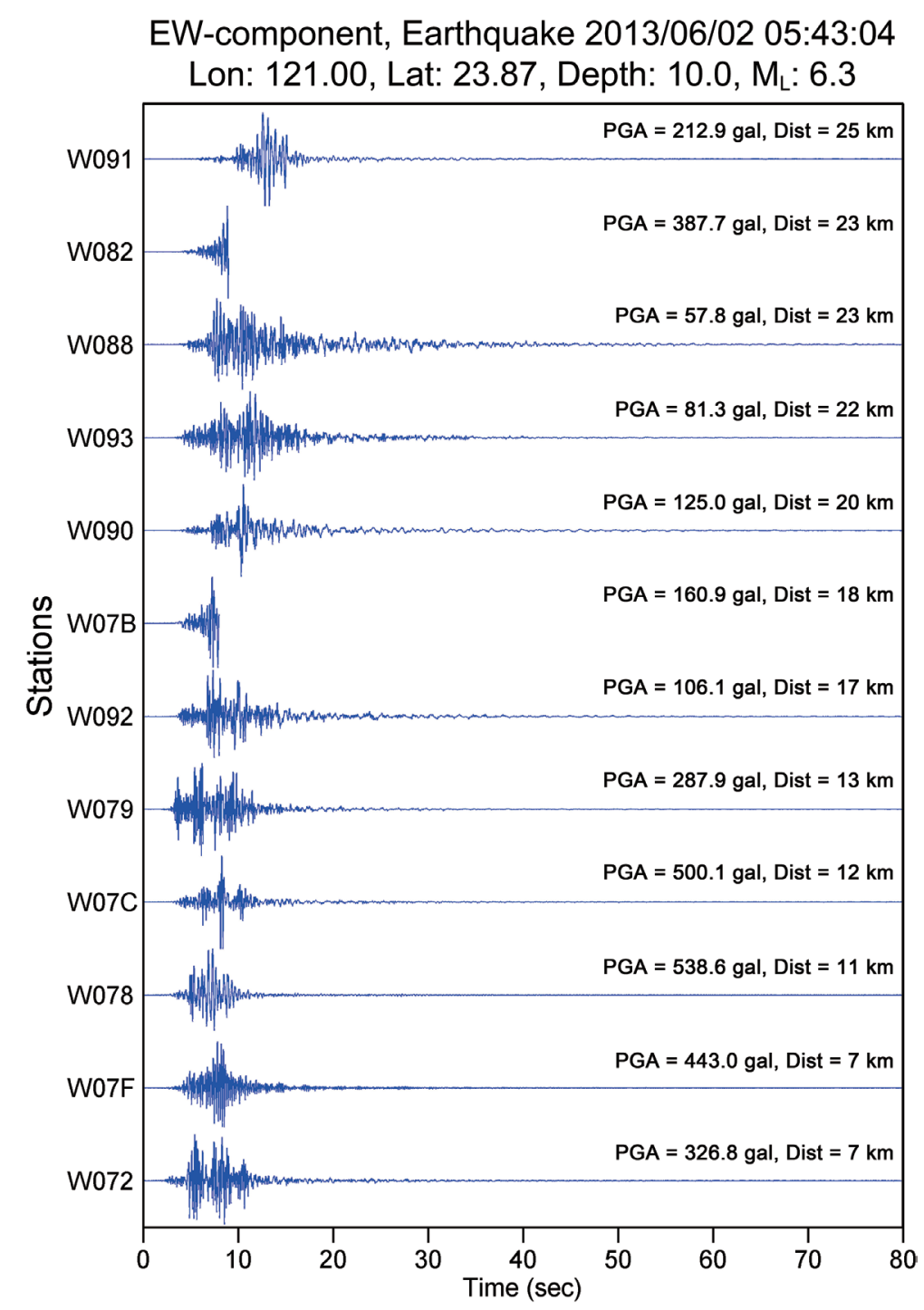

Fig. 7. Near epicentral strong motion records of the 2 June $2013 \mathrm{M}_{\mathrm{L}} 6.3$, Nantou Earthquake recorded by the Palert network. A few stations could not send data to the central stations, as generally occurring after $\mathrm{S}$ waves.

According to the proposal about 600 stations will be in operation after the project is completed. To make full use of limited and available resources, the NTU research team will focus on technology development and maintain close cooperation with the CWB, which is the official earthquake information reporting agency in Taiwan. Currently, the CWB system also receives signals transmitted by the NTU system. Thus, the CWB could combine two strong motion signal sources to produce shaking maps. As shown in Fig. 6, a combination of the two systems does help in making enhanced shaking maps which benefit disaster risk reduction, emergency preparations and emergency response.

Acknowledgements This research was supported by the Central Weather Bureau (CWB) and the Ministry of Science and Technology (MOST). The GMT software from Wessel and Smith (1998) was used in plotting part of the figures and are gratefully acknowledged. We would like to thank the constructive comments from Dr. Chien-Hsin Chang and the other two Reviewers.

\section{REFERENCES}

Allen, R. M., H. Brown, M. Hellweg, O. Khainovski, P. Lombard, and D. Neuhauser, 2009: Real-time earthquake detection and hazard assessment by ElarmS across California. Geophys. Res. Lett., 36, L00B08, doi: 10.1029/2008GL036766. [Link]

Chang, C. H., Y. M. Wu, D. Y. Chen, T. C. Shin, T. L. Chin, and W. Y. Chang, 2012: An examination of telemetry delay in the Central Weather Bureau Seismic Network. Terr. Atmos. Ocean. Sci., 23, 261-268, doi: 10.3319/ TAO.2011.11.29.01(T). [Link]

Chuang, R. Y., K. M. Johnson, Y. M. Wu, K. E. Ching, 
and L. C. Kuo, 2013: A midcrustal ramp-fault structure beneath the Taiwan tectonic wedge illuminated by the 2013 Nantou earthquake series. Geophys. Res. Lett., 40, 5080-5084, doi: 10.1002/grl.51005. [Link]

Cochran, E. S., J. F. Lawrence, C. Christensen, and R. S. Jakka, 2009: The Quake-Catcher Network: Citizen science expanding seismic horizons. Seismol. Res. Lett., 80, 26-30, doi: $10.1785 / \mathrm{gssrl} .80 .1 .26$. [Link]

Holland, A., 2003: Earthquake data recorded by the MEMS accelerometer: Field testing in Idaho. Seismol. Res. Lett., 74, 20-26, doi: 10.1785/gssrl.74.1.20. [Link]

Horiuchi, S., Y. Horiuchi, S. Yamamoto, H. Nakamura, C. Wu, P. A. Rydelek, and M. Kachi, 2009: Home seismometer for earthquake early warning. Geophys. Res. Lett., 36, L00B04, doi: 10.1029/2008GL036572. [Link]

Johnson, C. E., A. Bittenbinder, B. Bogaert, L. Dietz, and W. Kohler, 1995: Earthworm: A flexible approach to seismic network processing. IRIS, 14, 1-4.

Kanamori, H., 2005: Real-time seismology and earthquake damage mitigation. Annu. Rev. Earth Planet. Sci., 33, 195-214, doi: 10.1146/annurev. earth.33.092203.122626. [Link]

Wessel, P. and W. H. F. Smith, 1998: New, improved version of Generic Mapping Tools released. Eos, Trans. $A G U, 79,579$, doi: 10.1029/98EO00426. [Link]

Wu, Y. M. and H. Kanamori, 2005a: Rapid assessment of damage potential of earthquakes in Taiwan from the beginning of $P$ waves. Bull. Seismol. Soc. Am., 95, 1181-1185, doi: 10.1785/0120040193. [Link]

Wu, Y. M. and H. Kanamori, 2005b: Experiment on an onsite early warning method for the Taiwan early warning system. Bull. Seismol. Soc. Am., 95, 347-353, doi: 10.1785/0120040097. [Link]

Wu, Y. M. and T. L. Lin, 2014: A test of earthquake early warning system using low cost accelerometer in Hualien, Taiwan. In: Wenzel, F. and J. Zschau (Eds.), Early Warning for Geological Disasters - Scientific Methods and Current Practice, Advanced Technologies in Earth Sciences, Springer Berlin Heidelberg, New York, 253261, doi: 10.1007/978-3-642-12233-0_13. [Link]

Wu, Y. M., N. C. Hsiao, T. L. Teng, and T. C. Shin, 2002: Near real-time seismic damage assessment of the rapid reporting system. Terr. Atmos. Ocean. Sci., 13, 313 324.

Wu, Y. M., T. L. Teng, T. C. Shin, and N. C. Hsiao, 2003: Relationship between peak ground acceleration, peak ground velocity, and intensity in Taiwan. Bull. Seismol. Soc. Am., 93, 386-396, doi: 10.1785/0120020097. [Link]

Wu, Y. M., N. C. Hsiao, and T. L. Teng, 2004: Relationships between strong ground motion peak values and seismic loss during the 1999 Chi-Chi, Taiwan earthquake. Nat. Hazards, 32, 357-373, doi: 10.1023/ B:NHAZ.0000035550.36929.d0. [Link]

Wu, Y. M., T. L. Lin, W. A. Chao, H. H. Huang, N. C. Hsiao, and C. H. Chang, 2011: Faster short-distance earthquake early warning using continued monitoring of filtered vertical displacement: A case study for the 2010 Jiasian, Taiwan, earthquake. Bull. Seismol. Soc. Am., 101, 701-709, doi: 10.1785/0120100153. [Link]

Wu, Y. M., D. Y. Chen, T. L. Lin, C. Y. Hsieh, T. L. Chin, W. Y. Chang, W. S. Li, and S. H. Ker, 2013a: A highdensity seismic network for Earthquake Early Warning in Taiwan based on low cost sensors. Seismol. Res. Lett., 84, 1048-1054, doi: 10.1785/0220130085. [Link]

Wu, Y. M., C. H. Chang, H. Kuo-Chen, H. H. Huang, and C. Y. Wang, 2013b: On the use of explosion records for examining earthquake location uncertainty in Taiwan. Terr. Atmos. Ocean. Sci., 24, 685-694, doi: 10.3319/ TAO.2013.01.31.01(T). [Link]

Yu, S. B., H. Y. Chen, and L. C. Kuo, 1997: Velocity field of GPS stations in the Taiwan area. Tectonophysics, 274, 41-59, doi: 10.1016/S0040-1951(96)00297-1. [Link] 